\title{
Effective Use of ICT and Emerging Cellular Technologies for Health Care: E-Govt Reshaping Governance into Good Governance
}

\author{
F. Zafar, R. Saifullah Hassan, and Z. Mahmood
}

\begin{abstract}
This paper highlights best practices of technological influenced e-government using ICT, emerging mobile and web 2-0 technology for the effective health Care \& disease management system. Modern technology has given a whole new dimension to the concept of good governance, thus embarking a strong and effective influence on citizens and cultural trends. Authors have investigated successful case studies, which are taken from existing practice of egovernment health care projects within Pakistan.

Pakistan was hit by the epidemic of dengue, affecting over 350,000 people in 2010. Due to the unprecedented scale of epidemic, the basic health infrastructure was not ready to address the issue. However by 2012 a monitoring mechanism was devised as an e-Govt health care activity, to log all field activities related to prevention/eradication of the disease. The project focused mobile reporting using android phones, EDGE services, and Google maps. 650 smart phones users reported 43,000 activities. The information received was extrapolated to bring all stakeholders of anti-dengue campaign on a single platform and DIMS (Dengue Information Management System) was conceived. Features of DIMS include: 1) A central dashboard to view and dispose of complaints on real-time coming in from the Helpline and Hospitals e-CRS (Electronic Complaint Routing System). 2) Vector Surveillance System for tracking and reporting all indoor / outdoor larvaciding activities. 3) A Disease Reporting System to manage the clinical and lab diagnosis records of dengue affected patients.

Utilization of this system has resulted in $0 \%$ deaths reported due to dengue in the past 1.5 years. Careful investigation of step by step usage, reporting to DMIS with Android phone and working behavior of ICT infrastructure are elaborated in this research.
\end{abstract}

Index Terms-E-Govt., ICT, web 2.0, cellular technology, health.

\section{INTRODUCTION}

One of the major concerns of any Government, in favor of citizen's welfare is health care .However, health sciences over the last couple of decades depend more on IT centric initiatives to consolidate information of masses for meaningful usage and informed decision making. One of the major e-Govt Health Initiative has been witnessed working

Manuscript received May 20, 2013; revised July 28, 2013.

F. Zafar is with the Govt. College University, Lahore, Pakistan (e-mail: dr.f.zafar@gcu.edu.pk).

R. Saifullah Hassan is with the University of Engineering and Technology, Lahore, Pakistan (e-mail: r_saifullah@hotmail.com).

Z. Mahmood is with the University of Derby, UK \& North West University, Unit of Business Mathematics and Informatics, Potchefstroom, South Africa (e-mail: dr.z.mahmood@hotmail.co.uk). effectively in Pakistan to deal with Dengue epidemic.

Pakistan especially Punjab has been hit by vector-borne disease of Dengue reporting 26,270 effected cases. Non availability of historical data in an organized manner represents challenge for early detection of any future outbreaks thus limiting the capability of government for early preparedness and emergency response. However in developing country like Pakistan, e-Govt has played vital role for health care using emerging Cellular and web 2.0 technologies involving smart phones and geo tagging in order to overcome the epidemic of Dengue .This practice was initiated within Punjab, which was reported the largest epidemic of dengue worldwide. Dengue, which is a mosquito -borne viral infection is conventionally referred as break bone fever. It is an infectious or transmittable tropical disease caused by the dengue virus [1]. A mild dengue victim develop symptoms as fever, head ache, muscle and joint pains and in severe cases it develops life threatening Dengue High Fever (DHF), which exhibits bleeding, low levels of blood platelets and blood plasma leakage casing risk of death within 5-7 working days. Dengue epidemic has touched the alarming situation globally with thousands of fatalities world-wide since 2001.

\section{A. Medication}

There is no medication and available vaccine in market which claims to reduce the risk of dengue virus.

\section{B. Prevention}

Scientists and experts have agreed that the prevention is sought by reducing the habitat and the number of mosquitoes and limiting exposures to mosquito bites from dawn to dusk [2].

\section{Effective E-Govt Role and Solution}

Disease surveillance and reporting MIS system, Geo tagging of snapshots taken of Dengue larva cites by field officers, digital centralized Dashboards managing all information, Location tracking of Patients infectious with disease and timely availability of blood donor for DHF patients using e-blood line, Training and use of state of the arts web 2.0 services and Smart phones with Android application, Custom built mobile application development for extremely response Citizen-Govt linkage for Dengue Activity Tracing and complaints registration against any District Health Officers and other e-Govt stakeholder who does not co-operate with citizens regarding health issues, and DSIM with GIS maps along with centralize dash boards to manage and analyze all information in order to provide 
rapid strategic solution.

\section{LITERATURE REVIEW}

The first suspected dengue-like epidemics emerged in the Americas in the 1600s, and by the 1800 s, were common in port cities across the region, from the Caribbean to South America. In 1934 Dengue impacted about 10\% of the population and it spread through Florida and South Georgia [3], [4]. The first mosquito eradication effort was in 1901 in Cuba, and by the mid-20th century, only one dengue virus strain (DENV-2, genotype V) seemed to be in circulation. The number of reported dengue cases increased considerably in the early 1980s; one of the worst outbreaks of that period in Cuba, during 1981 resulted in 344,000 cases.

\section{Dengue Statistics AROUND THE WORLD}

The World Health Organization estimates that more than 2.5-3 billion people, or more than 40 percent of the world's population, are now at risk of being infected with dengue [5].

The Most targeted regions of the disease are SE Asia [6] and the Western Pacific (Fig. 1), but within past few years, a rising trend is witnessed in South America and the Caribbean [3]. Average annual number of DF/DHF cases reported to World Health Organization along an average annual number of countries reporting dengue is shown in fig 1 below [1]. By 2010, Dengue came up as a severe transmissible disease for more than half of the world's population, and thereby in 2013 , the statistics still revealed the critical condition of the severity of the issue and the dengue plasmodium in Latin America and South East Asia[3], [7]. The threat of a possible outbreak of dengue fever now exists in Europe and local transmission of dengue was reported for the first time in France [8] and Croatia [9] in 2010 .

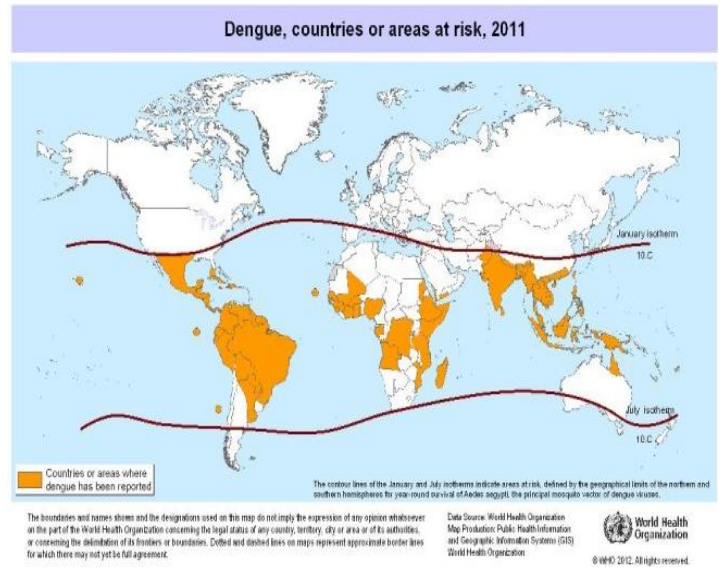

Fig. 1. Dengue, countries or areas at risk, 2011.

A recent (2012) outbreak of dengue on Madeira Islands of Portugal has resulted in over 1800 cases [10]. An estimated 500000 people with severe dengue require hospitalization each year, a large proportion of whom are children. About $2.5 \%$ of those affected die. In the past few years, cases of dengue have popped up in Texas, Florida,
France, and Croatia. Of the 500,000 cases of severe dengue requiring hospitalization and the roughly 24,000 deaths they cause each year [11], most are in children, according to the WHO [5]. A recent study estimated that there were more people at risk of dengue infection calculating that up to 3.97 billion people are at risk in 128 countries [12] (See Fig 1). Approximately 50 million infections occur annually with 500000 cases of DHF (Fig. 2).

It is also estimated that there are 22,000 deaths per year, and mainly among children. Only in India, 37 million dengue cases have been reported with 227500 hospitalizations [2], [6]. Health authorities in Brazil have reported more than 200,000 dengue infected people within first seven weeks of 2013 as compared with 70,000 in the same period last year, thus, indicating a steep rise in confirmed cases.

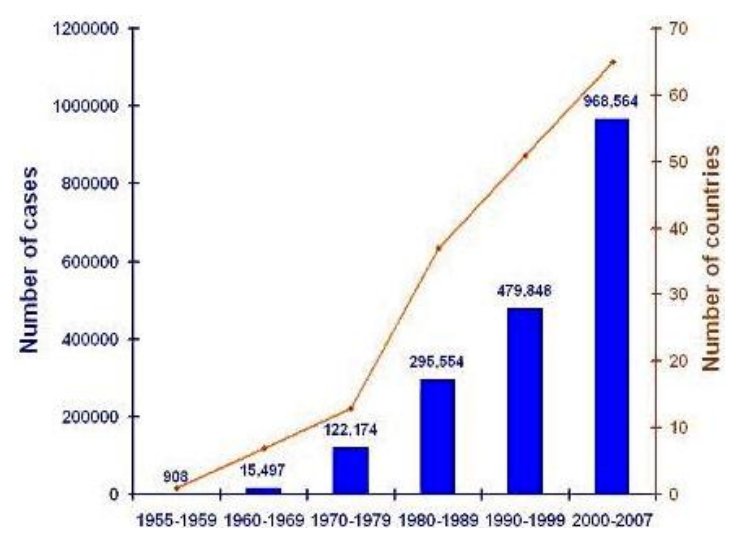

Fig. 2. DF /DHF cases reported to WHO [2].

\section{A. WHO Strategy Report Targets Dengue}

WHO has highlighted the increased stress and target of Dengue fever in its recent report (Fig 3), Global Strategy for Dengue Prevention and Control, has already set a goal of cutting deaths caused by dengue by $50 \%$ along with $25 \%$ reduction in effected cases over the next 8 years.

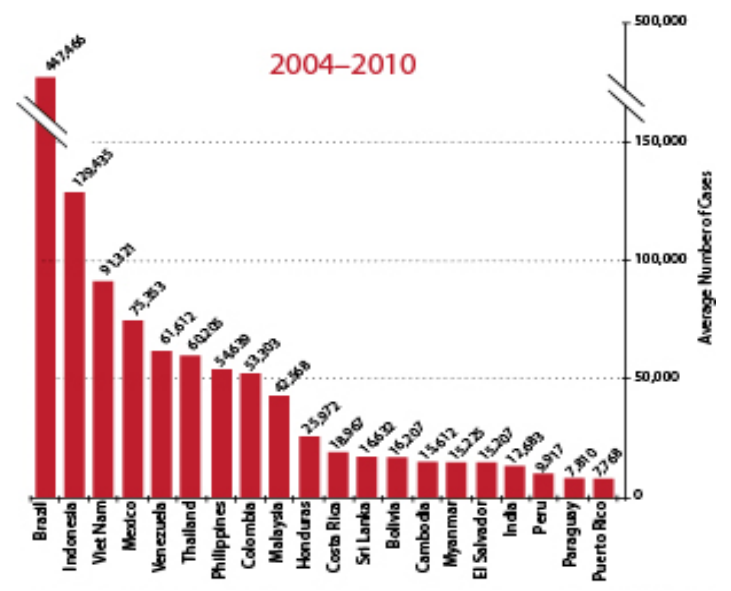

Fig. 3. Average number of dengue cases in highly endemic countries.

\section{B. Dengue in America}

From the beginning of 2013 up to epidemiological week (EW) 21 in the Region of the America, hundreds of thousands dengue cases have been reported [1]. 
TABLE I: DENGUE CASES REPORTED WORLD WIDE-2012

\begin{tabular}{|c|c|c|}
\hline Registered Cases & Severe Dengue & Death \\
\hline 868,653 & 8,406 & 346 \\
\hline
\end{tabular}

The escalation of dengue fever incidence in Latin America - with more than 1.1 million cases reported in 2012 poses a serious public health threat. Table I shows the ratio of dengue spread in world and in 2012. Fig. 4 shows Dengue outbreaks in America within 2008 until 2010 and it is clearly shown in Fig. 5 that 1.1 million cases have been reported in USA only in 2012 [3].

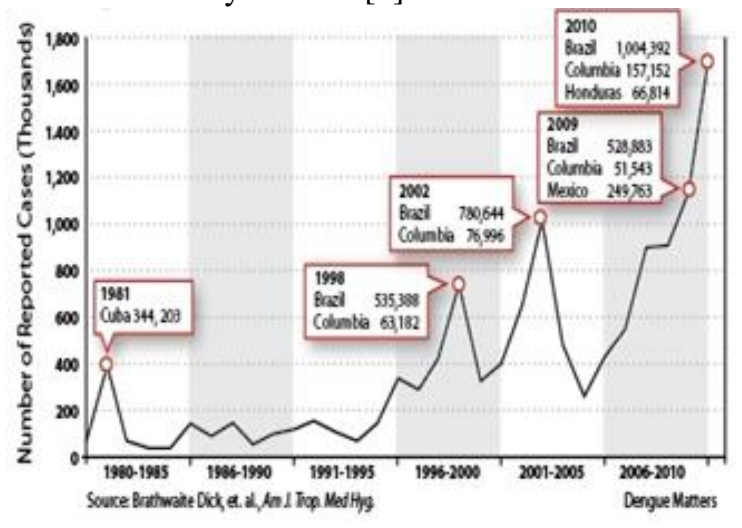

Fig. 4. Dengue outbreaks in the Americas, 2008-2010 [13].

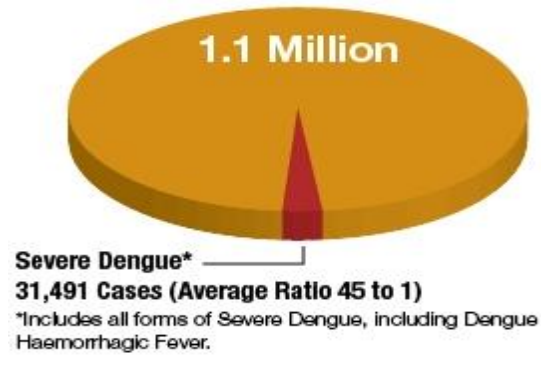

Fig. 5. Reported dengue cases in the Americas-2012 [13].

\section{Dengue in Germany}

Given are the statistics representing dengue attacking Germany from 2001 to 2010 where it is observed that in 2007 and onward dengue cases were reported double and three times in numbers as reported previously [14] (See Table II).

TABLE II: DENGUE CASES REPORTED FROM 2001 TO 2010

\begin{tabular}{|l|l|}
\hline Year & Number of Recorded Cases \\
\hline 2001 & 60 \\
\hline 2002 & 213 \\
\hline 2003 & 131 \\
\hline 2004 & 121 \\
\hline 2005 & 144 \\
\hline 2006 & 175 \\
\hline 2007 & 264 \\
\hline 2008 & 273 \\
\hline 2009 & 298 \\
\hline 2010 & 387 \\
\hline
\end{tabular}

\section{Dengue in China}

A total of 655,324 cases were reported from 1978 to 2008 , resulting in 610 deaths [15]. However since 1990s, dengue epidemics have spread gradually from Guangdong, Hainan, and Guangxi provinces in the southern coastal regions to the relatively northern and western regions including Fujian, Zhejiang, and Yunnan provinces [16]. Latest Statistics show
12,435 cases have been reported in 2013 until July (See Table III).

TABLE III: DENGUE CASES AND DEATH COUNT-2013

\begin{tabular}{|l|l|l|}
\hline Distribution & Reported Cases & Deaths \\
\hline China & 12,435 & 47 \\
\hline ILOILO City & 1,805 & 14 \\
\hline Cabatuan & 219 & 4 \\
\hline
\end{tabular}

\section{E. Dengue in SA}

Only within South Asia until June 2013, a total of 145,496 cases have been reported for dengue causing 528 deaths [17], [18] (See Table IV).

TABLE IV: DENGUE CASUALTIES IN SA-2013

\begin{tabular}{|l|l|l|}
\hline Country & $\begin{array}{l}\text { Reported } \\
\text { Cases }\end{array}$ & Fatalities \\
\hline Singapore & 13,047 & 05 \\
\hline Malaysia & 10,400 & 22 \\
\hline Sri Lanka & 16,000 & 29 \\
\hline Myanmar & 6,448 & 13 \\
\hline India & 50,000 & 242 \\
\hline Indonesia & 3,119 & 14 \\
\hline Maldives & 4,482 & 10 \\
\hline Philippines & 42,000 & 193 \\
\hline
\end{tabular}

However recent research statistics show an interesting figure coming out of Pakistan within SA. Table V below shows that in the year 2010, a total of 26270 cases were reported, whereas in 2011 a total of 21000 cases were reported ending up with 512 fatalities, which gradually decreased down to reported cases being 894 in the year 2012 causing 12 deaths and in 2013, only 11 cases are reported with $0 \%$ fatality rate [19].

TABLE V: Dengue Statistics in PunJab-PAKistan [19]

\begin{tabular}{|l|l|l|}
\hline Year & Reported Cases & Fatalities \\
\hline 2013 & 11 & 0 \\
\hline 2012 & 894 & 12 \\
\hline 2011 & 21,000 & 512 \\
\hline 2010 & 26,270 & 256 \\
\hline
\end{tabular}

This dramatic reduction in dengue victims and death counts is only possible due to few initiates which were taken by Government under its e-government sector [20]. The next section describes DMIS which was a disaster management and health care system planned, developed and successfully launched by Punjab Government [21]. Beyond political and economic factors, the dengue problem is exacerbated by climatic factors such as heavy rainfall and monsoon season .Since dengue fever is said to be a climatesensitive disease that becomes more pronounced when hard rains hit and thus during monsoon from June-August its more likely to hit Pakistan and similarly in any part of the world. Research and studies have shown a clear correlation between incidence of dengue fever and heavy rainfall in tropical and subtropical regions. Heavy rainfall causes standing water, and encourages people to keep more water around the home to deal with future shortages-both of which create more breeding areas for the Aedes mosquitoes that transmit dengue.

This is only the virtue of DMIS that dengue is controlled $100 \%$ which is a big success of utilizing proper ICT as remedial measure for health care facilitation. As according to WHO, there is no specific treatment for dengue/ severe dengue, but early detection and access to proper medical 
care lowers fatality rates below 1\% [22], [23]. Dengue prevention and control solely depends on effective vector control measures.

\section{USE of EMERging CEllular, Web 2.0 TECHNOLOGY IN HEALTH CARE}

In February 2012, responding to the thousands of the cases being reported already in the preceding years, the Punjab government initiated monitoring mechanism, which was devised to $\log$ all field activities related to prevention/eradication of the disease. The system as devised back then is still operational and entomologists/field officers report activities on regular basis. The tasks taken by the governmental field officers extends from awareness to community, removal of debris, identification of ponding, larviciding and IRS (spraying) at premises of confirmed patients [20].

The project focuses on reporting using cellular and web 2.0 technologies, taking e-measure to combat the disease in Pakistan. Each member in the field is provided with an android smartphone who reports there and then using edge services. Given are the details of project initiated and successfully launched by e-Govt within Pakistan to overcome dengue.

\section{Dims-Dengue InFormation MANAGEMENT SySTEM}

DIMS is a central dashboard for all stakeholders to view and dispose of complaints on real-time coming in from the Helpline and Hospitals e-CRS (Electronic Complaint Routing System). It is an efficient Vector Surveillance System for track/report of larvaciding activities. Furthermore a Disease Reporting System is embedded as key feature in order to manage the clinical and lab diagnosis records of dengue affected patients.

\section{Value Propositions}

- Real time coordination amongst departments.

- Used for early outbreak detection for epidemics with the help of geographically mapping of patient's data.

- An avenue for citizens to register the complaints and comments on the government department's performance.

- Real time control of management and efficiency of concerned departments through centralized dashboard.

- A contact center platform used to respond in emergencies e.g. track spurious PIC drug issue, this system was used to guide the patients and generate required MIS.

- Campaign management tool, e.g. It is also being used to register complaints regarding the ongoing Polio campaign and monitor the same via GIS maps.

- $\quad$ Platform for disease reporting by public, government hospitals and private health practitioners.

DIMS is divided in 4 sub Projects, which are deployed with highest level of cellular technology using smart phones. The interface is provided and monitored via smart web 2.0 systems at client /server ends. However it is notable that these sub projects have the capacity to operate and execute their functionality independently as well. The projects are named as:

- Dengue Activity Tracking System

- Geo-Tagged e-Blood Line and Blood / Donor inventory system

- $\quad$ Punjab Health Line

- Disease Surveillance System

\section{Dengue ACtivity Tracking System}

This is first phase of DMIS which works independently as well as in conjunction with other sub projects.

\section{Procedure}

The user takes a geo-tagged photograph while performing the designated task. Field officers are also mandated to identify breeding hotspots and remove them accordingly, two separate photographs are submitted highlighting before and after activities clearly [24]. Data stream as submitted via smart phones gets plotted onto Google maps. Fig 6 shows an activity for the removal of waste material and debris where dengue larvae are prone to breed.

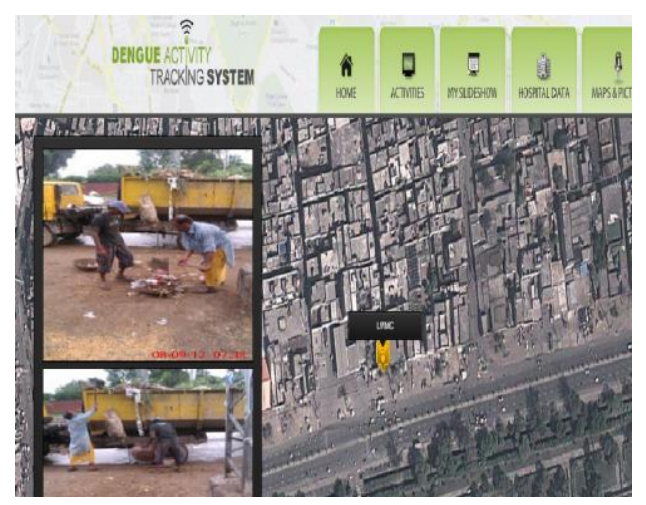

Fig. 6. Geo Tagged Picture send and reception on DMIS web 2.0 Portal [24].

Data stream as submitted via smart phones gets plotted onto Google maps. Fig. 7 shows dengue activity tracking system within Lahore on this Dengue Activity Tracking portal and is highlighted in red dots across various regions of Lahore city. The report and plotted disease can be seen on day to day to monthly scale basis for 1 year at a time.

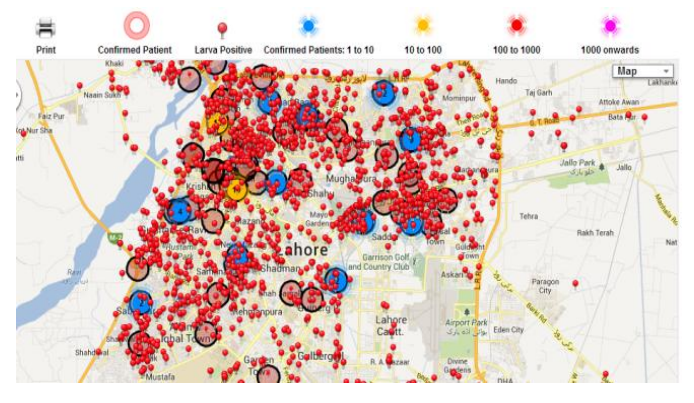

Fig. 7. Dengue activity tracking system portal for Lahore [21]

A record is generated at the end of e-Govt health portal and given is an activity graph which shows number of picture count taken for purpose of reporting over the portal and it shows that more than 88,000 activities were lodged and prompt action was taken by e-Govt DMIS [20](See Fig 8 ). 


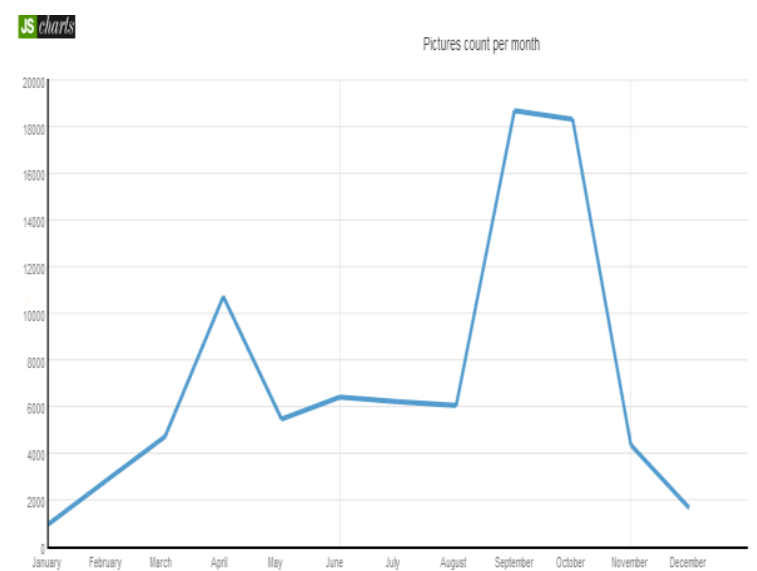

Fig. 8. Yearly activity log of geo tagged pictures [24].

\section{GeO TAGGED E-BLOOD LINE AND BLOOD/DONOR INVENTORY SYSTEM}

E-Blood line is an initiative taken by the government in order to connect the right donor with needful patient at the right time. The establishment of a blood inventory system and creation of a blood donor database with geographical tagging and cell phone ID pivoted over Call Centre services is established to deal with dengue epidemic, so as to mobilize and organize willing donors in order to cope with blood shortage[24]. Since Dengue fever results in loss of blood platelets and white blood cells, therefore in severe conditions, to avoid possible fatality, patients are required to get infused with healthy blood to overcome deficiency in White Blood Cells. Government data and statistics s describes more than 600,000 blood donations per year in Pakistan [19].

\section{Procedure}

A distinct feature of this project is that, patient's family cannot contact PBL donors directly. Only blood banks, which meet the project requirements, can launch blood requisitions on PBL online portal. Call Center Agents (CCAs) contact the active donors from that particular area and direct the willing donors to the blood bank which raised the blood requisition. In this way a buffer is created between donors and patients, so that either party does not face any undue pressure. A centralized PBL online portal enables resource sharing between blood banks for better crisis management, which has drastically reduce the wastage of blood bags.

\section{Punjab Health Line-A Call Centre}

DMIS takes logs and records from health line call center as well. After being victimized for Dengue over 350,000 people in 2010, Government formulated e-health line to take immediate measures with needed solution [21]. This Call Center was established in a record time of 48 hours for counseling the citizens $24 / 7$ and was manned by 150 doctors taking calls on a toll free helpline - thus, The Punjab eHealth Line came into being and was managed under Punjab Information Technology Board[19], [20]. The objectives of this Call Center establishment that were added over period of time included:
- $\quad$ Patient counseling

- Preventive measures to the citizens

- Advise on treatment protocol to health practitioners

- $\quad$ Logging of Fumigation Service requests

- $\quad$ Solid Waste Disposal requests

- WASA/ Sanitation related requests

- Complaints (Over charging by laboratories, Private hospitals, Govt. hospitals, etc.)

The information received at the Call Centre was further extrapolated to bring all stakeholders of anti-dengue campaign on a single platform and send to DIMS (Dengue Information Management System).

\section{Disease Surveillance System}

\section{Procedure}

To start with, Teaching Hospitals, Tehsil Headquarters (THQs) and District Headquarters (DHQs) are manned with dedicated data entry operators, who are responsible to report cases as per the predefined templates. The data entry interface is exposed to Government Hospitals via secured usernames and passwords. Disease wheels are planned to be provided to respective Health Officers and District In charges, who report disease cases via SMS [21].

DSS as envisioned uses SatScan and Early Aberration Reporting System (EARS) as used by Centre of Disease Control and Prevention in USA[19]. Targeted to ensure emergency response and preparedness, the system connects all stakeholders to respond to any alarming situation in a coordinated manner. The project features of DSS are:

- Case detection, case registration, case confirmation and case supervision.

- Data Analysis and Interpretation.

- $\quad$ Representation on GIS Maps.

- Timely escalation and Intimations.

- District/Tehsil and UC wise disease widespread trends.

- Dispersion of disease over time, space or space and time.

- Time periodic disease surveillance for early detection of disease outbreaks

The project is live in four hospitals named DHQ Shiekhupura, THQ Muridke, Children Hospital and Mayo Hospital where results are getting compiled for finalization of implementation strategy throughout Punjab with more than 25 departments involved and 550+ users reporting [20].

\section{CONClusion}

DIMS has proven to be an effective ICT project, initiated by e-Govt sector within country .Utilization of this system has effectively resulted in $0 \%$ deaths reported due to dengue in the past 1.5 years within the same region .A country which is globally worst effected target of dengue with 35000 dengue patients has achieved Nil death count and dramatically reduced number of 11 disease infected cases in the year 2013. Role of government in terms of public welfare and health policies has been reshaped with utilization of emerging tools in cellular communication. DIMS, along with e-health facilities including Disease Surveillance System, Geo-Tagged e-Blood Line and Blood/Donor inventory system, Punjab Health Line 
practices by e-Govt are directly associated with common citizen in terms of cure or fearing risk of fatality .This ICT infrastructure can help any other country facing dengue epidemic to overcome and effectively control the situation. In addition, the same projects can help to be utilized in surveillance and monitoring of other fatal diseases like measles etc. This E-Govt health care facilitation however has attained a bench mark of confidence over the political establishment and it was evident in the recent elections of 2013, that the governance act and political establishment, who has initiated these e-health activities and projects was heavily appreciated by public, and this and citizen-togovernment trust has taken new shape, by earning vote of trust by common citizens and resulting overall establishment of improved Govt-to-Citizen and citizen-to Govt relationship as seen in the 2013 election results. Eventually health care policy and tools by e-government has changed impression of government into and good governance within Pakistan.

\section{REFERENCES}

[1] World Health Organization, "Dengue and severe dengue," Fact Sheet, no. 117, Nov. 2012.

[2] National Travel Health Network and Centre UCLH NHS Foundation Trust, "Health Professionals," Fact Sheet, 2013.

[3] S. Pasteur, "Spotlight on Dengue in the Americas, Dengue matters," AHFS Category, vol. 4, 2012

[4] Dialogues on the Impact of The Environment on the Public health and the human condition. Dengue News, woodshed environment coalition. (2013). [Online]. Available: http://woodshedenvironment.wordpress.com/breaking-news/

[5] Guzman, Alfonso, and R. E. Istúriz. "Update on the global spread of dengue," International journal of antimicrobial agents, 2010.

[6] E. E. Ooi and D. J Gubler, "Dengue in Southeast Asia: epidemiological characteristics and strategic challenges in disease prevention," Cad Saude Publica., 2009.

[7] V. Arenas and P. Zanotto, "Worldwide spread of Dengue Virus Type 1," PLoS ONE, vol. 8, no. 5, 2013.

[8] M. Touraine, (September 13, 2010). Le Ministère de la Santé et des Sports. First indigenous case of dengue isolated in France. [Online]. Available: http://www.sante-sports.gouv.fr/premier-cas-autochtoneisole-de-dengue-en-france-metropolitaine.html

[9] I. Margan, B. Aleraj et al., (August-September 2010). Autochthonous dengue fever in Croatia. [Online]. Available: http://www.eurosurveillance.org/ViewArticle.aspx?ArticleId=19805

[10] Fact Sheet for Health Professionals, European Center for Disease Prevention and Control (ECDC), May 2013. pp. 1-2

[11] L. M. Ling, A. W. Smith, and Y. S. Leo. "Fulminant hepatitis in dengue haemorrhagic fever," Journal of clinical virology, vol. 38, no. 3, pp. 265-268, 2007

[12] J. Oliver, W. Peter et al., "Refining the global spatial limits of dengue virus transmission by evidence-based consensus," PLoS Neglected Tropical Diseases 6, no. 8, 2012.

[13] J. S. Chanasit, M. Haditsch, I. Schöneberg, S. Günther, K. Stark, and C. Frank, "Dengue virus infection in a traveller returning from Croatia to Germany," Euro Surveill, vol. 15, no. 40, 2010.

[14] B. Aleraj, D. Krajcar et al., "Autochthonous dengue fever in Croatia, August-September 2010," Euro Surveill, vol. 16, no. 9, 2011.

[15] L. Bai, L. C. Morton, and Q. Liu, "Climate change and mosquitoborne diseases in China: a review," Journal of Global Health, vol. 9, no. 10,2013

[16] W. J. Ya, L. Z. Rong, J. Anthony, and C. X. Guang, "Dengue Fever in Mainland China," Am J Trop Med H, vol. 83, no. 3, pp. 664-671, 2010.

[17] T. Bolken, C. M. Byrd, D. Dai, D. E. Hruby, and R. Jordan, "Antiviral drugs for treatment or prevention of Dengue infection," $U$. S. Patent, Dec 4, 2008

[18] H. Lei Win. (June 2013). Dengue fever cases hit a high in parts of Southeast Asia. Thomson Reuters Foundation. [Online]. Available: http://www.trust.org/

[19] Government of Punjab, "Project report Sector Wise 2011-2012," Punjab Information Technology Board, 2011.
[20] S. R. Sheikh, "E-Govt initiatives for Health, joint director E-Govt and industry," Punjab Information Technology Board, 2013.

[21] B. Munir, "Disease Surveillance," Punjab Information Technology Board, 2013.

[22] Impact of Dengu - Global Alert and Response. (2012). World Health Organization. [Online]. Available: http://www.who.int/csr/disease/dengue/impact/en/

[23] Y. S. Leo et al., "Immunogenicity and safety of recombinant tetravalent dengue vaccine (CYD-TDV) in individuals aged 2-45 years: Phase II randomized controlled trial in Singapore," Human Vaccines \& Immunotherapeutics, vol. 8, no. 9, pp. 1259-1271, 2012.

[24] F. Mehta, "Dengue tracking and Punjab blood line, senior project manager - Plan 9 \& e-Governance," Punjab Information Technology Board, 2013.

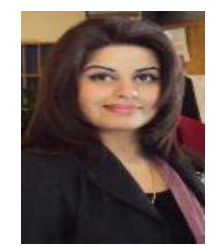

Fareeha Zafar was born in 1978 in Lahore, Pakistan. She has received $\mathrm{PhD}$ in computer Sciences in particular Mobile Cellular networks from University of Derby-United Kingdom in 2009. She also has MBA-HRM, M.Phil. Comp.Sc-UK, M.Sc. Software Engineering Pakistan and M,Sc Networks from Pakistan. Fareeha Zafar also holds CCNA, CCNA, CCIT, C-Voice and CCIE certifications. She is senior faculty for IT and Business over 13 years among which she taught 6years in UK .At present she is employed with HEC Pakistan and deputed as Assistant Professor at Govt. College university Lahore, Pakistan. Fareeha is Research Head for mobile \& Communication advancements as well as for e-Practices for Business Management \& ICT for e-Govt. She is also In charge of $\mathrm{PhD}$ program at Govt. College university Lahore.

Dr. Zafar has over 24 research papers and she is executive Editor of Science International Journal- Lahore. She is reviewer and member editorial board of ABSRC, WASET, CISCO, ACM and multiple journals and books. She is associate to multiple foreign Universities for ICT \& business Schools in Europe, Asia, and Africa. Dr. Zafar's research includes e-Govt practices \& polices, Cloud Computing, Wireless Sensor Networks, Mobile Communications, LTE, Mobile $\mathrm{RF}$ and Tele medicine.

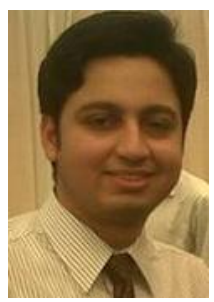

Rana Saifullah Hassan was born in 1991 in Lahore, Pakistan. He is perusing his MS at Institute of Business and Management, University of Engineering and Technology, Lahore. He has received his B.Sc. in Business Accounting \& Finance from GC University Lahore, Pakistan. He is an enthusiastic Research associate for e-Practices for Business Management and ICT for e-Govt. He is closely working in group with Fareeha Zafar managing domains of e-practices in particular e-Govt. Rana has 4 publications in reputed Journals and is author for multiple chapters on e-Govt within IGI book series and is active journalist with leading newspapers within Pakistan. Rana has served multiple organizations in capacity building, Accounting and Human Resource Management.

Mr. Hassans research interest revolves around e-governance, practical projects and solution for e-Govt issues, Social media, emerging technologies, Web \& ICT at business, Human Resource Management and e-Banking.

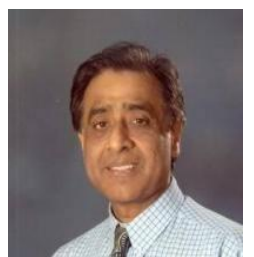

Zaigham Mahmood is a professor who has an M. Sc in Computer Sciences from Pakistan where he was born, and after which he received $\mathrm{PhD}$ in Modeling of Phase Equilibrium from UK. His experience in education sector spans over three decades. He is currently at Univ of Derby UK as well as with the Unit of Business Mathematics and Informatics North West Univ Potchefstroom S. Africa where he is a Professor Extraordinaire. He is also a technology consultant at Debesis Education UK.

Dr. Mahmood has more than 100 publications in leading journals and is an author of 10 books on various topics spanning from cloud computing to e-government .He is Editor-in-Chief of Journal of EGovernments Studies and Best Practices as well as Editor-in-Chief of book Series on E-Government, Digital Divide and Regional Development with IGI Global. His research interests include e-Govt, Project Management and Cloud Computing. 